\title{
Smoking Cessation Among Racial/Ethnic Minorities, 2010-2014
}

\author{
Monica Webb Hooper • Brooke G. Rogers • \\ Kolawole Okuyemi
}

Published online: 22 January 2015

(C) Springer International Publishing AG 2015

\begin{abstract}
The purpose of this study was to systematically review recent empirical literature on smoking cessation in racial/ethnic minority groups. Specifically, we focused on smoking cessation intervention trials and investigations of factors associated with cessation. Studies published between 2010 and September 2014 were considered. Nine smoking cessation intervention trials and 16 studies examining correlates of smoking behavior were published in within the past 3 years. Results demonstrated promise for varenicline in facilitating cessation among African Americans and Hispanics, and culturally specific behavioral counseling appears to be efficacious among Asian Americans. In trans-group comparisons, racial/ethnic minorities reported greater quit attempts compared to Whites; yet success may be reduced due to factors such as menthol smoking, low pharmacotherapy use, and lower readiness to quit. Recommendations for evidence-based interventions and future research are offered.
\end{abstract}

Keywords Smoking $\cdot$ Smoking cessation $\cdot$ Racial $\cdot$ Ethnic . Minorities · African Americans · Hispanics $\cdot$ Latinos · Asian Americans $\cdot$ Pacific Islanders $\cdot$ American Indians/Native Alaskans $\cdot$ Native Hawaiians $\cdot$ Multiracial $\cdot$ Systematic review $\cdot$ Varenicline $\cdot$ Counseling $\cdot$ Pharmacotherapy

This article is part of the Topical Collection on Tobacco

M. Webb Hooper $(\bowtie)$

University of Miami, Sylvester Comprehensive Cancer Center,

PO Box 248185, Coral Gables, FL, USA

e-mail:mwebb@miami.edu

B. G. Rogers

University of Miami, PO Box 248185, Coral Gables, FL, USA

e-mail: brogers@psy.miami.edu

K. Okuyemi

University of Minnesota, 717 Delaware Street SE, Minneapolis, MN, USA

e-mail: kokuyemi@umn.edu

\section{Introduction}

Eliminating racial/ethnic disparities in tobacco-related outcomes is a public health priority. The leading causes of death in several racial/ethnic minority groups are attributable to tobacco [1-4]. From 2005 to 2012, the prevalence of smoking in the USA declined in every racial/ethnic minority group, with the exception of those reporting multiple races [5]. The greatest decrease in smoking rate was observed among American Indians/Native Alaskans (31.9\%), followed by Hispanics (22.8\%), Asian Americans (19.6\%), and African Americans $(15.8 \%)$. In contrast, the prevalence among multiracial smokers increased by $5.2 \%$ during that time period. Despite previous reviews indicating a greater proportion of cessation studies focused on African Americans relative to the other racial/ethnic minority groups [6-8], the smoking decline in this population was the lowest (excluding multiracial smokers). Moreover, no previous reviews have examined studies targeting smokers of multiple races.

The overarching goal of this article was to provide recommendations for evidence-based interventions as indicated by the most recent literature. We systematically reviewed and evaluated cessation interventions in racial/ethnic minorities and factors related to smoking status. Our a priori search parameters included published studies on US adult smokers from 2010 to September 2014, randomized or quasiexperimental trials, behavioral and pharmacological interventions, national and convenience surveys of smoking behavior, and secondary analyses of correlates of cessation-related behaviors. Research specifically focused on adolescent, pregnant, or patient samples were excluded. Searches were conducted in Web of Science, PsychInfo, and PubMed electronic databases. The Boolean search terms included smoking, cessation, correlates, predictors, factors, randomized trial, and racial ethnic minorities (substituting African American, Black, Hispanic, Asian, Native Hawaiian, Pacific Islander, Native 
American Indian, multiple races, multiracial, biracial, disparities, minority for race, and ethnicity). The search results yielded 72 articles, with a significant proportion investigating medical conditions that included smoking status as a covariate. We systematically refined each search by adding terms to narrow the number of publications. The search was considered complete when the search term combinations yielded duplicate or unrelated articles. We also examined article reference lists to identify additional studies. The final search yielded 38 studies ( $n=9$ smoking cessation intervention trials in at least one racial/ethnic minority group, $n=11$ examining factors associated with smoking cessation, and $n=18$ examining correlates of cessation-related cognitions and behaviors). ${ }^{1}$ The following sections review recent research in each of these domains by racial/ethnic category. Finally, we offer conclusions regarding the state of the science and directions for future research.

\section{Smoking Cessation Interventions in Racial/Ethnic Minorities}

Table 1 summarizes recent smoking cessation studies targeting racial/ethnic minorities.

African Americans One publication between 2010 and 2014 was identified that tested the effects of a smoking cessation treatment in African Americans. Nollen et al. [9•] tested the efficacy of open-label varenicline, administered for 3 months, plus five adherence support counseling sessions or one standard care session. Overall, abstinence rates through 3 months ranged from 15.3 to $23.6 \%$, with no differences between conditions. However, varenicline adherence was positively associated with cessation at month 3 . Limitations of the study, including the small pilot sample and the unmatched intervention intensity, preclude conclusions regarding the efficacy of adherence support counseling in this population. As aptly noted by Nollen et al. [9•], abstinence rates were lower in this trial compared to primarily White samples. Indeed, Schnoll et al. [10] found that relative to Whites, racial/ethnic minorities (mostly African American) were less likely to quit following a 12-week open-label varenicline plus counseling program.

Hispanics/Latinos Three trials were published that examined smoking cessation interventions among US Hispanics from 2010 to 2014 . Borrelli et al. [11] tested the effects of culturally tailored counseling among Hispanic caregivers of a child with asthma. Participants received three home visits consisting of either motivational interviewing or a control intervention, which was based on the 2000 tobacco clinical practice guidelines [12]. Participants who set a quit date also received

$\overline{{ }^{1} \text { There were } 16}$ (of 29) unique correlational studies.
8 weeks of nicotine patches. They found greater cessation rates in the culturally tailored condition compared to control, but the differences were not statistically significant. In contrast to hypotheses, they found greater decreased in secondhand smoke exposure in the control, which seemed to be a function of greater smoking reduction in that group. Despite numerous strengths of the study, such as the comparative effectiveness design, inclusion of Hispanic smokers across the readiness to quit continuum, and consideration of Hispanic cultural values, the study was underpowered to determine significant effects.

Cabriales et al. [13] tested the efficacy of a brief smoking cessation intervention among light and intermittent Hispanics of primarily Mexican heritage. Using a randomized, delayed control design, participants received a 30-35-min motivational enhancement/health education session immediately or at the 3-month follow-up. No difference in perceived confidence to quit or 30-day cessation was found between conditions $(5.6 \%$ immediate versus $4.7 \%$ delayed). However, readiness to quit was greater in the immediate intervention versus delayed control group. This study was limited by high attrition and reliance on self-reported cessation.

Finally, De Dios et al. [14 $]$ conducted a pilot study comparing cessation outcomes between varenicline and nicotine replacement therapy (NRT) among Hispanic light smokers. Participants were randomly assigned to receive a 30-min culturally informed behavioral session and either 12 weeks of varenicline, nicotine patches, or placebo varenicline. Intentto-treat analyses demonstrated significant effects of varenicline (versus the other conditions) at the 2, 3, and 4month assessments. Treatment efficacy may have been limited by poor treatment adherence across conditions, high proportion $(25-40 \%)$ of incomplete data, and the small sample.

Asian Americans, Native Hawaiians, and Pacific Islanders Three recent trials examined smoking cessation interventions in pan-Asian samples. McDonnell et al. [15] tested the efficacy of an internet-based smoking cessation intervention compared to written self-help in a sample of Korean Americans. Both interventions were informed by community-based participatory principles and cognitive behavioral strategies. At 50 weeks, there was no difference in cessation between conditions; yet, the likelihood of cessation was significantly greater among participants who completed the online intervention.

Zhu et al. [16••] conducted a randomized controlled trial (RCT) to test the efficacy of multilingual quitline counseling (plus self-help materials) versus self-help materials only. Participants received up to six sessions delivered in Chinese, Korean, or Vietnamese. The counseling condition demonstrated significantly greater cessation overall and within each language at 4 and 7-months compared to self-help materials. Although results of the study were strongly in favor of quitline counseling tailored to the Asian community, limitations were 


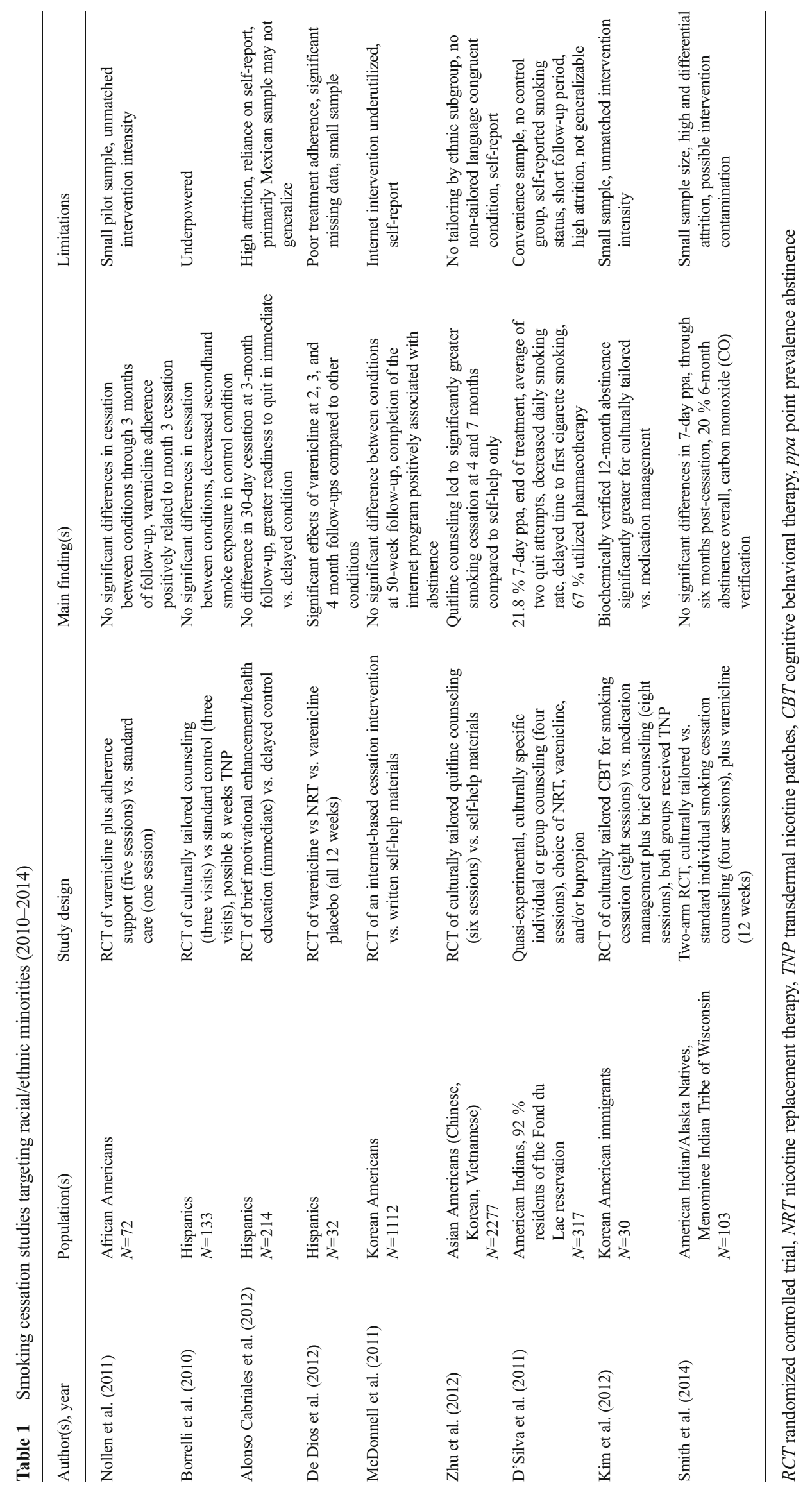


that counseling was not tailored by subgroup and that a nontailored, but language congruent condition was not included.

Finally, Kim et al. [17] conducted a two-arm randomized trial to compare culturally tailored cognitive behavioral therapy (CBT) for smoking cessation to medication management among Korean Americans. Both conditions received 8 weeks of transdermal nicotine patch (TNP), and were followed for 6months post-cessation. Biochemically confirmed cessation was greater in the CBT condition versus medication management. Limitations of the study included the small sample $(N=$ 30) and unmatched intervention intensity.

American Indians/Native Alaskans Two studies were published between 2010 and 2014 that examined the effects of smoking cessation interventions among American Indians/ Native Alaskans. D'Silva et al. [18] evaluated the effects of a culturally specific counseling intervention (four sessions of group or individual) plus pharmacotherapy among American Indians using a quasi-experimental design. Self-reported cessation was $21.1 \%$ at intervention completion, and $21.8 \%$ at the 3-month follow-up. The study was limited by lack of randomization, high attrition, and reliance on selfreported cessation.

Smith et al. [19] examined the efficacy of a culturally tailored versus standard smoking cessation treatment an American Indian/Alaska Native tribal community. All participants received four individual counseling visits and 12 weeks of varenicline. Cessation rates ranged from 14 to $44 \%$ across the six smoking status assessments through 6-months postcessation, with no differences between conditions. Post hoc analyses indicated that the 6-month abstinence was associated with early cessation, older age, lower daily smoking intensity at baseline, and little to no smoking among partners or family members. Study limitations included the small sample, possible intervention contamination, and differential attrition between conditions. Also noted were challenges related to the university-tribal collaboration.

Smokers of More than One Race No intervention studies targeted smokers of more than one race (i.e., biracial or multiracial) or reported separate outcomes for this population.

Summary In summary, relatively few smoking cessation intervention trials have been conducted in underrepresented racial/ethnic minority groups within the past 3 years. The current review suggests that varenicline adherence may promote cessation among African Americans, though supplemental adherence counseling may not confer an additional advantage. There is initial support for the promise of varenicline among Hispanics, although further research is needed. In contrast, culturally specific behavioral approaches, specifically faceto-face and telephone quitline counseling, appear to be efficacious among Asian Americans. Internet-based intervention trials for smoking cessation are scant in these populations, yet this approach was unsupported in one study in an Asian American sample.

\section{Factors Associated with Smoking Cessation Among Racial/Ethnic Minorities}

Identifying variables that are related to smoking cessation in underrepresented racial/ethnic minority communities is important in enhancing intervention effects and ultimately eliminating health disparities. As summarized in Table 2, race/ethnicity, behavioral, and cultural factors are predictive of cessation across a range of study designs in studies published over the past 5 years. Three studies investigated behavioral factors, including choice of cigarettes, pharmacotherapy use, and quit attempts. Stahre et al. [20] examined relationships between race/ethnicity and cessation in a nationally representative survey. They found that African Americans and Hispanics were less likely to report quitting compared to Whites and non-Hispanics, respectively. There were no differences in quit ratios between Whites, Asian Americans, or American Indian/Alaska Natives. National surveys also found that a preference for mentholated cigarettes was inversely associated with cessation across populations [20], particularly among African Americans, Whites, and Puerto Ricans [20, 21]. One survey found that smoking menthol cigarettes was positively related to cessation among Mexican Americans [21]. Quit attempts are also a known predictor of smoking cessation, but few studies have considered the associations between race/ethnicity, the origins of attempts, and abstinence. Resnicow et al. [22] examined the relationship between planning to quit and length of abstinence in a sample of African Americans, Whites, and Hispanics. Among Whites, unplanned quit attempts (versus planned quitting) were related to more days of abstinence. In contrast, the length of abstinence was greater in African Americans for planned quit attempts, but this relationship did not reach statistical significance.

There are seven Federal Drug Administration (FDA) pharmacotherapies for smoking cessation. Research investigating their influence among racial/ethnic minorities is limited. Faseru et al. [23] was the first to investigate predictors of smoking abstinence among African Americans enrolled in an RCT testing the efficacy of bupropion. They found that treatment with bupropion was positively predictive of shortterm (week 7), but not longer-term (week 26) abstinence. Shelley et al. [24] conducted an open-label prospective cohort study of 6 weeks of transdermal nicotine patch (TNP) therapy among low-income Chinese smokers. The intent-to-treat cessation rate at 4 -months was $26.7 \%$, and $44.7 \%$ among selfreported patch users. Cessation was positively associated with 
Table 2 Factors associated with smoking cessation among racial/ethnic minorities (2010-2014)

\begin{tabular}{|c|c|c|c|c|}
\hline Factor & Author(s) & Population(s) & Study design & Main finding(s) \\
\hline Race/ethnicity & Stahre (2010) & $\begin{array}{l}\text { AA, W, H, AI/NA, } \\
\text { AAm } \\
N=13,285\end{array}$ & National survey & $\begin{array}{l}W \text { : greater quit ratio vs. AA, no difference } \\
\text { vs. AI/NA, AAm } \\
\text { Non-H: greater quit ratios vs. H }\end{array}$ \\
\hline Quit attempts & Resnicow (2014) & $\begin{array}{l}\text { AA, W, H } \\
N=1127\end{array}$ & Online panel survey & $\begin{array}{l}W \text { : unplanned quit attempts positively } \\
\text { associated with length of abstinence }\end{array}$ \\
\hline \multirow[t]{2}{*}{ Pharmacotherapy use } & Faseru (2013) & $\begin{array}{l}\text { AA } \\
N=540\end{array}$ & RCT enrollees & $\begin{array}{l}A A \text { : bupropion positively associated with } \\
7 \text { week, but not } 26 \text {-week abstinence }\end{array}$ \\
\hline & Shelley (2010) & $\begin{array}{l}\mathrm{CA} \\
N=375\end{array}$ & Open-label cohort study enrollees & $\begin{array}{l}\text { Chinese: smoking while wearing TNP } \\
\text { inversely associated with cessation }\end{array}$ \\
\hline \multirow[t]{2}{*}{$\begin{array}{l}\text { Menthol cigarette } \\
\text { preference }\end{array}$} & Stahre (2010) & $\begin{array}{l}\text { AA, W, H, AI/NA, } \\
\text { AAm } \\
N=13,285\end{array}$ & National Survey & $\begin{array}{l}\text { AA: lower odds of cessation vs. White } \\
\text { non-menthol smokers } \\
\text { Overall: inverse association with cessation }\end{array}$ \\
\hline & Delnevo (2011) & $\begin{array}{l}\text { AA, W, H } \\
N=71,193\end{array}$ & National survey & $\begin{array}{l}A A, W, P R: \text { inverse association with cessation } \\
M A: \text { positive association with cessation }\end{array}$ \\
\hline Acculturation & Garcia (2010) & $\begin{array}{l}\text { Filipino immigrants } \\
N=318\end{array}$ & Convenience survey & $\begin{array}{l}F \text { : English use with family/friends positively } \\
\text { associated with cessation }\end{array}$ \\
\hline Health literacy & Stewart (2014) & $\begin{array}{l}\text { AA, W, O } \\
N=200\end{array}$ & RCT enrollees & $\begin{array}{l}\text { Analyses adjusted for race: inversely } \\
\text { associated with smoking relapse }\end{array}$ \\
\hline Health behaviors & Berg (2012) & $\begin{array}{l}\text { AA } \\
N=539\end{array}$ & RCT enrollees & $\begin{array}{l}A A \text { : fruit and vegetable consumption, } \\
\text { reduced smoking, walking/exercise } \\
\text { positively associated with cessation }\end{array}$ \\
\hline $\begin{array}{l}\text { Home smoking } \\
\text { restrictions }\end{array}$ & Garcia (2010) & $\begin{array}{l}\text { Filipino immigrants } \\
N=318\end{array}$ & Convenience survey & $F$ : positively associated with cessation \\
\hline Financial strain & Kendzor (2010) & $\begin{array}{l}\text { AA, W, H } \\
N=424\end{array}$ & Intervention enrollees & All: inverse association with abstinence \\
\hline
\end{tabular}

All African Americans, Whites, Hispanics, Asian Americans/Pacific Islanders, American Indians/Alaska Natives, Multiracial; $A A$ African Americans; $W$ Whites; $H$ Hispanics; $A I / N A$ American Indians/Native Americans; $A A m$ Asian Americans; NH Native Hawaiians; PIPacific Islanders; $M R$ Multiracial; $O$ Others; F Filipinos; $C A$ Chinese Americans; EA East Asians; PR Puerto Ricans; $M A$ Mexican Americans; $R C T$ randomized controlled trial

greater self-efficacy and health concerns, and inversely associated with smoking while wearing TNP.

Cultural factors may also be related to smoking cessation, yet the literature in this area is in its infancy. The prevalence of smoking among Hispanics is likely to increase with greater acculturation to the USA [25]. Acculturated Hispanics may be at higher risk for tobacco-related diseases than Whites, partly due to less education and longer smoking duration [26]. Li et al. [27] found that smoking prevalence varied significantly across Asian communities (Chinese, Korean, Asian Indians, and other Asian subpopulations) by acculturation (language spoken at home). Only one study examined acculturative factors with respect to smoking cessation. Garcia et al. [28] found that among male Filipino immigrants, smoking cessation was positively associated with speaking English with friends and family.

Four studies examined associations between individualdifference factors and smoking cessation with a focus on racial/ethnic differences. A robust literature has demonstrated the inverse association between financial strain and cessation, which was supported in a diverse sample of African Americans, Whites, and Hispanics [29]. New findings are beginning to emerge for smoking cessation correlates in other areas. Stewart [30] considered the role of health literacy in smoking relapse among racially/ethnically diverse treatment-seekers and found an inverse association. Although the study included African Americans, Whites, and "Others," interactions between health literacy and race/ethnicity on relapse were not reported. Berg et al. [31] demonstrated that positive crossover healthy lifestyle changes are associated with smoking reductions and cessation among African Americans. Specifically, cutting down or cessation at week 26 was positively associated with increased fruit and vegetable consumption and walking for exercise. Finally, home smoking restrictions have also been related to cessation in previous research, and a positive relationship was also noted among Filipino immigrants surveyed about tobacco use [28].

\section{Correlates of Cessation-Related Cognitions and Behaviors}

Several recent studies have examined correlates of smokingrelated behavior changes in racially/ethnically diverse samples. Five studies investigated racial/ethnic differences in quit 
attempts using survey methods. In a random-digit-dial telephone survey of Whites, African Americans, and Hispanics, Nonnemaker et al. [32] found that potential antismoking advertisement exposure (measured by television gross rating points) was positively associated with quit attempts in Whites and Hispanics. Confirmed advertisement recall was positively related to quit attempts among Whites and African Americans, with the highest odds of making a quit attempt associated with emotional or graphic images. This study was limited by its cross-sectional design and non-representation of other racial/ ethnic groups. Rafful et al. [33] examined sociodemographic correlates of quit attempts in a nationally representative sample of smokers. They found that the odds of making a quit attempt during a 3-year period were lower among Hispanics and Asians, compared to Whites. Kahande et al. [34] focused specifically on correlates of past-year quit attempts across racial/ethnic groups and found more attempts among multiracial (51.9 \%) and Hispanic (47.6\%), compared to White smokers (43\%). Across groups, the likelihood of making a quit attempt increased with education, home smoking restrictions, and physician's advice to quit, and decreased with age, greater smoking intensity and duration, and smoking upon awakening. Interactions with race/ethnicity indicated that among African Americans, menthol cigarette smoking was positively associated with quit attempts, while non-menthol smoking was associated with quit attempts among Whites and multiracial participants. Physician advice was positively related to quit attempts in all groups, except for Asian Americans/Pacific Islanders and American Indians/Alaska Natives. Finally, Stahre [20] examined relationships between quit attempts and race/ethnicity in a nationally representative survey. Compared to Whites and American Indians/Alaska Natives, African Americans and Asian Americans reported greater past-year quit attempts.

Pharmacotherapies for smoking cessation increase the odds of cessation [35], yet are underutilized among racial/ethnic minorities. Five studies examined racial/ethnic differences in attitudes, knowledge, and use of FDA-approved pharmacotherapy. Ryan et al. [36] found that African Americans reported less positive attitudes and were less likely to ever use an FDA-approved cessation aid compared to Whites. Among Native Hawaiians, Filipinos, East Asians, Whites, and Others (African Americans, Hispanics) in Hawaii, Herzog, and Pokhrel [37] found that each of the ethnic minority groups reported less knowledge regarding cessation aids compared to Whites, and that Native Hawaiians and Filipinos were less likely to use them. This study, however, was limited by use of a convenience sample, and combining heterogeneous subgroups to increase statistical power. Stahre et al. [20] found that American Indians/Alaska Natives were less likely to utilize cessation aids during past-year attempts compared to other racial/ethnic groups.
Motivational factors, such as readiness to quit smoking, are predictive of abstinence in the general population of smokers [38]. Three studies examine race/ethnic differences in readiness to quit, two among treatment-seekers, and one in a national survey. Webb Hooper et al. [39] found that help-seeking African Americans reported greater depressive symptoms and lower readiness to quit compared to Whites and Hispanics. In addition, Herzog and Pokhrel [37] found that Native Hawaiians reported lower readiness to quit compared to Whites. Finally, Mukherjea et al. [40] found greater desire to quit among Asian Americans, Native Hawaiians, and Pacific Islanders (AANHPIs) compared to non-AANHPIs.

In summary, race/ethnic differences exist in smokingrelated cognitions and behaviors. Racial/ethnic minority smokers may be more likely to attempt cessation, yet are less successful compared to Whites. This may be related to the greater propensity to smoke menthol cigarettes, lower likelihood of pharmacotherapy use, and lower readiness to quit.

\section{Conclusions}

In the period of the current review (2010-2014), there were relatively few studies focused on racial/ethnic minority smokers, particularly with respect to interventions or factors related to cessation. Of the studies that do include smokers from diverse racial/ethnic backgrounds, most do not include adequate representation from Asian Americans, Pacific Islanders, American Indians/Native Alaskans, Native Hawaiians [e.g., 10, 29, 32, 41] or multiracial smokers [e.g., 10, $29,32,33,41]$. Moreover, consideration of race/ethnic differences including these groups is lacking [e.g., 30, 42]. The findings of this review indicate several new possibilities for intervening with racial/ethnic minority smokers. Although more research is needed, varenicline appears to facilitate cessation among African Americans and Hispanics. Behavioral interventions have demonstrated positive effects among Asian Americans, particularly those that are culturally specific. Special efforts must be undertaken to increase inclusion in randomized intervention trials, as racial/ethnic minority smokers may be less likely to enroll even when they are eligible [10].

Consistent with prior research, racial/ethnic minority groups are more likely than Whites to attempt cessation, but have lower odds of success. First, this lack of success may be due in part to the strong preference for menthol cigarettes in racial/ethnic minority populations. Menthol smokers demonstrate higher serum nicotine, cotinine, and expired carbon monoxide levels compared to non-menthol smokers [43], which may facilitate dependence. Indeed, racial/ethnic minority smokers who prefer menthol brands have greater difficulty achieving abstinence [20]. Second, the most consistent finding from recent research is the lower likelihood of using pharmacotherapy among racial/ethnic minorities. Attempts to quit in 
these populations might be derailed by the combination of dependence on higher nicotine-containing cigarettes and the lack of a pharmacologic aid to mitigate withdrawal symptoms. Third, readiness to quit may be lower in some racial/ethnic minority groups. Quit attempts that occur in the absence of readiness (psychoeducation about cessation, withdrawal, and relapse prevention) may be less likely to be successful.

The prevalence of smoking among individuals identified as belonging to more than one racial group warrants attention. There were no intervention studies focused on multiracial smokers, and a minority of studies reported outcomes for this group. The crude categorization of individuals into one racial/ ethnic group precludes a focus on smokers who self-identify as biracial or multiracial. In some cases, this group was described as "Other," and was not consistently included in analyses. This omission may be explained in part by the interest in describing discrete racial/ethnic categories with regard to smoking and disparities, and/or small sample sizes. Given that "Multiracial" was only racial/ethnic category to show an increase in smoking [5], we propose that smokers of multiple races should be included on the list of "priority" populations in tobacco control. Using data from a nationally representative sample of adolescents and young adults, Clark et al. [44] found that biracial and multiracial respondents reported higher smoking prevalence rates relative to monoracial/monoethnic groups. They suggest that the blending of environments (e.g., family, social) may interact with SES to result in unique pathways to substance use initiation and/or cessation. Previous research suggests that bi- and multiracial individuals experience discrimination [e.g., group membership rejection; 45] and acculturative stress [46], which could inhibit cessation. Indeed, this group may be a significantly greater risk of smoking relapse compared to Whites [42]. With the changing demographics of the USA and the inclusion of biracial and multiracial on the census, future research is needed targeting this population.

On the basis of this review, we offer four recommendations for evidence-based treatment of racial/ethnic minority smokers. First, given the high interest in cessation, greater attention is needed on preparation for making a quit attempt. Psychoeducational (versus motivational) interventions to increase readiness to quit are important. Such interventions would encourage preparing and planning ahead of the target cessation date and address concerns about pharmacotherapy. Second, strong messages about using and adhering to pharmacotherapy in all quit attempts are essential, which may be best delivered by healthcare providers [47] and/or lay health promoters [48]. Third, it is essential that interventions be designed to resonate with the particular population by incorporating cultural factors, primary language, emotional and graphic imagery, and lower reading levels, as appropriate. Finally, we recommend encouraging multiple lifestyle changes within the context of cessation interventions, such as improving nutrition and physical activity, and implementing smoking restrictions in the home environment.

Much more research is needed that focuses on understanding smoking cessation and relapse in underrepresented racial/ ethnic populations. Moreover, the literature on factors associated with cessation and intervention efficacy among biracial/ multiracial smokers is in its infancy. Increasing the understanding of mechanistic contributors, mediators and moderators, of the race/ethnicity-smoking cessation relationship is also important. To date, little is known about factors that explain the association between race/ethnicity and smoking cessation in these populations. There is some suggestion that cultural factors and acculturative processes play a role in smoking status. However, theoretically grounded investigations with a priori hypotheses based on established or new models are needed to inform the field about how these constructs impact tobacco use and cessation. Although most studies examining various aspects of race and smoking have focused on African Americans, this population continues to experience the most pervasive tobacco-related health disparities. Accordingly, more research is needed in this group. Research is also needed among Asian Americans, Pacific Islanders, American Indians/Alaska Natives, Native Hawaiians, and smokers belonging to more than one race, as they are almost entirely overlooked in this domain.

\section{Compliance with Ethics Guidelines}

Conflict of Interest Monica Webb Hooper, PhD, Brooke G. Rogers, $\mathrm{MPH}$, and Kolawole Okuyemi, MD, MPH declare that they have no conflict of interest.

University of Minnesota has received an FDA-approved multi-centered research grant from Pfizer.

Human and Animal Rights and Informed Consent This article does not contain any studies with human or animal subjects performed by any of the authors.

\section{References}

Papers of particular interest, published recently, have been highlighted as:

- Of importance

•- Of major importance

1. Howe HL, Wu X, Ries LA, Cokkinides V, Ahmed F, Jemal A, et al. Annual report to the nation on the status of cancer, 1975-2003, featuring cancer among U.S. Hispanic/Latino populations. Cancer Am Cancer Soc. 2006;107(8):1711-42.

2. Chen MS, Hawks BL. A debunking of the myth of healthy AsianAmericans and pacific islanders (vol 9, p 261, 1995). Am J Health Promot. 1995;9(6):435.

3. Mokdad AH, Marks JS, Stroup DF, Gerberding JL. Actual causes of death in the United States, 2000. JAMA J Am Med Assoc. 2004;291(10):1238-45. 
4. Society AC. Cancer facts \& figures for African Americans 2013 2014. Atlanta: American Cancer Society; 2013.

5. Agaku IT, King BA, Dube SR. Current cigarette smoking among adults-United States, 2005-2012. MMWR Morbid Mortal Wkly Rep. 2014;63(2):29-34.

6. Lawrence D, Graber JE, Mills SL, Meissner HI, Warnecke R. Smoking cessation interventions in US racial/ethnic minority populations: an assessment of the literature. Prev Med. 2003;36(2): 204-16.

7. Liu JJ, Wabnitz C, Davidson E, Bhopal RS, White M, Johnson MRD, et al. Smoking cessation interventions for ethnic minority groups - a systematic review of adapted interventions. Prev Med. 2013;57(6):765-75.

8. Cox LS, Okuyemi K, Choi WS, Ahluwalia JS. A review of tobacco use treatments in U.S. ethnic minority populations. Am J Health Promot AJHP. 2011;25(5 Suppl):S11-30.

9. Nollen NL, Cox LS, Nazir N, Ellerbeck EF, Owen A, Pankey S, et al. A pilot clinical trial of varenicline for smoking cessation in black smokers. Nicotine Tob Res. 2011;13(9):868-73. This study was a pilot trial examining the efficacy of varenicline among African American adults. Although there were no differences between the adherence support and standard conditions, greater varenicline adherence was positively associated with abstinence.

10. Schnoll RA, Cappella J, Lerman C, Pinto A, Patterson F, Wileyto $\mathrm{EP}$, et al. A novel recruitment message to increase enrollment into a smoking cessation treatment program: preliminary results from a randomized trial. Health Commun. 2011;26(8):735-42.

11. Borrelli B, McQuaid EL, Novak SP, Hammond SK, Becker B. Motivating Latino caregivers of children with asthma to quit smoking: a randomized trial. J Consult Clin Psychol. 2010;78(1): 34-43.

12. Fiore MC, Bailey WC, Cohen SJ, Dorfman SF, Fox BJ, Goldstein $\mathrm{MG}$, et al. A clinical practice guideline for treating tobacco use and dependence — a US Public Health Service report. JAMA J Am Med Assoc. 2000;283(24):3244-54.

13. Cabriales JA, Cooper TV, Salgado-Garcia F, Naylor N, Gonzalez E. A randomized trial of a brief smoking cessation intervention in a light and intermittent Hispanic sample. Exp Clin Psychopharmacol. 2012;20(5):410-9.

14. de Dios MA, Anderson BJ, Stanton C, Audet DA, Stein M. Project impact: a pharmacotherapy pilot trial investigating the abstinence and treatment adherence of Latino light smokers. J Subst Abus Treat. 2012;43(3):322-30. This study examined the efficacy of varenicline among Latino adults. They found that varenicline was superior to control at 2, 3, and 4-month assessments. They concluded that this may be a promising treatment among Latinos.

15. McDonnell DD, Kazinets G, Lee HJ, Moskowitz JM. An internetbased smoking cessation program for Korean Americans: results from a randomized controlled trial. Nicotine Tob Res. 2011;13(5): 336-43.

16.• Zhu SH, Cummins SE, Wong SS, Gamst AC, Tedeschi GJ, ReyesNocon J. The effects of a multilingual telephone quitline for Asian smokers: a randomized controlled trial. J Natl Cancer Inst. 2012;104(4):299-310. This study tested the efficacy of language congruent qutline counseling among Asian Americans. Results demonstrated significantly greater smoking cessation in the language-translated condition compared to control. The authors concluded that providing quitline counseling is the primary language of Asian American callers enhances cessation rates.

17. Kim SS, Kim SH, Ziedonis D. Tobacco dependence treatment for Korean Americans: preliminary findings. J Immigr Minor Health. 2012;14(3):395-404.

18. D'silva J, Schillo BA, Sandman NR, Leonard TL, Boyle RG. Evaluation of a tailored approach for tobacco dependence treatment for American Indians. Am J Health Promot. 2011;25(5):S66-9.
19. Smith SS, Rouse LM, Caskey M, Fossum J, Strickland R, Culhane $\mathrm{JK}$, et al. Culturally tailored smoking cessation for adult American Indian smokers: a clinical trial. Couns Psychol. 2014;42(6):852-86.

20. Stahre M, Okuyemi KS, Joseph AM, Fu SS. Racial/ethnic differences in menthol cigarette smoking, population quit ratios and utilization of evidence-based tobacco cessation treatments. Addiction. 2010;105:75-83.

21. Delnevo CD, Gundersen DA, Hrywna M, Echeverria SE, Steinberg MB. Smoking-cessation prevalence among US smokers of menthol versus non-menthol cigarettes. Am J Prev Med. 2011;41(4): 357-65.

22. Resnicow K, Zhou Y, Scheuermann TS, Nollen NL, Ahluwalia JS. Unplanned quitting in a triethnic sample of U.S. smokers. Nicotine Tob Res. 2014;16(6):759-65.

23. Faseru B, Nollen NL, Mayo MS, Krebill R, Choi WS, Benowitz $\mathrm{NL}$, et al. Predictors of cessation in African American light smokers enrolled in a bupropion clinical trial. Addict Behav. 2013;38(3): 1796-803

24. Shelley D, Nguyen N, Peng CH, Chin M, Chang MD, Fahs M. Increasing access to evidence-based smoking cessation treatment: effectiveness of a free nicotine patch program among Chinese immigrants. J Immigr Minor Health. 2010;12(2):198-205.

25. Abraido-Lanza AF, Chao MT, Florez KR. Do healthy behaviors decline with greater acculturation? Implications for the Latino mortality paradox. Soc Sci Med. 2005;61(6):1243-55.

26. Burns EK, Levinson AH, Lezotte D, Prochazka AV. Differences in smoking duration between Latinos and Anglos. Nicotine Tob Res. 2007;9(7):731-7.

27. Li S, Kwon SC, Weerasinghe I, Rey MJ, Trinh-Shevrin C. Smoking among Asian Americans: acculturation and gender in the context of tobacco control policies in New York City. Health Promot Pract. 2013;14(5 Suppl):18S-28.

28. Garcia GM, Romero RA, Maxwell AE. Correlates of smoking cessation among Filipino immigrant men. J Immigr Minor Health. 2010;12(2):259-62.

29. Kendzor DE, Businelle MS, Costello TJ, Castro Y, Reitzel LR, Cofta-Woerpel LM, et al. Financial strain and smoking cessation among racially/ethnically diverse smokers. Am J Public Health. 2010;100(4):702-6.

30. Stewart DW, Cano MA, Correa-Fernandez V, Spears CA, Li YS, Waters AJ, et al. Lower health literacy predicts smoking relapse among racially/ethnically diverse smokers with low socioeconomic status. BMC Public Health. 2014;14:14.

31. Berg CJ, Thomas JL, An LC, Guo HF, Collins T, Okuyemi KS, et al. Change in smoking, diet, and walking for exercise in blacks. Health Educ Behav. 2012;39(2):191-7.

32. Nonnemaker JM, Allen JA, Davis KC, Kamyab K, Duke JC, Farrelly MC. The influence of antismoking television advertisements on cessation by race/ethnicity, socioeconomic status, and mental health status. Plos One. 2014;17:9(7).

33. Rafful C, Garcia-Rodriguez O, Wang S, Secades-Villa R, MartinezOrtega JM, Blanco C. Predictors of quit attempts and successful quit attempts in a nationally representative sample of smokers. Addict Behav. 2013;38(4):1920-3.

34. Kahende JW, Malarcher AM, Teplinskaya A, Asman KJ. Quit attempt correlates among smokers by race/ethnicity. Int J Environ Res Public Health. 2011;8(10):3871-88.

35. Fiore MC, Jaen CR, Baker TB, Bailey WC, Bennett G, Benowitz $\mathrm{NL}$, et al. A clinical practice guideline for treating tobacco use and dependence: 2008 update - a US Public Health Service report. Am J Prev Med. 2008;35(2):158-76.

36. Ryan KK, Garrett-Mayer E, Alberg AJ, Cartmell KB, Carpenter MJ. Predictors of cessation pharmacotherapy use among Black and non-Hispanic White smokers. Nicotine Tob Res. 2011;13(8): 646-52. 
37. Herzog TA, Pokhrel P. Ethnic differences in smoking rate, nicotine dependence, and cessation-related variables among adult smokers in Hawaii. J Commun Health. 2012;37(6):1226-33.

38. Biener L, Abrams DB. The contemplation ladder - validation of a measure of readiness to consider smoking cessation. Health Psychol. 1991;10(5):360-5.

39. Hooper MW, Baker EA, McNutt MD. Racial/ethnic differences among smokers: revisited and expanded to help seekers. Nicotine Tob Res. 2014;16(5):621-5.

40. Mukherjea A, Wackowski OA, Lee YO, Delnevo CD. Asian American, Native Hawaiian and Pacific Islander tobacco use patterns. Am J Health Behav. 2014;38(3):362-9.

41. Woodruff SI, Zuniga ML, Lawrenz J. Ethnoracial differences in emergency department patients' tobacco use. Nicotine Tob Res. 2011;13(11):1037-44.

42. Weinberger AH, Pilver CE, Mazure CM, McKee SA. Stability of smoking status in the US population: a longitudinal investigation. Addiction. 2014;109(9):1541-53.

43. Williams JM, Gandhi KK, Steinberg ML, Foulds J, Ziedonis DM, Benowitz NL. Higher nicotine and carbon monoxide levels in menthol cigarette smokers with and without schizophrenia. Nicotine Tob Res. 2007;9(8):873-81.

44. Clark TT, Nguyen AB, Kropko J. Epidemiology of drug use among biracial/ethnic youth and young adults: results from a U.S. population-based survey. J Psychoactive Drugs. 2013;45(2): 99-111.

45. Yoo HC, Gee GC, Lowthrop CK, Robertson J. Self-reported racial discrimination and substance use among Asian Americans in Arizona. J Immigr Minor Health. 2010;12(5):683-90.

46. Zamboanga BL, Schwartz SJ, Jarvis LH, Van Tyne K. Acculturation and substance use among Hispanic early adolescents: investigating the mediating roles of acculturative stress and self-esteem. J Prim Prev. 2009;30(3-4):315-33.

47. Cox LS, Cupertino AP, Tercyak KP. Interest in participating in smoking cessation treatment among Latino primary care patients. J Clin Psychol Med Settings. 2011;18(4):392-9.

48. Carter-Pokras OD, Feldman RH, Kanamori M, Rivera I, Chen L, Baezconde-Garbanati L, et al. Barriers and facilitators to smoking cessation among Latino adults. J Natl Med Assoc. 2011;103(5): 423-31. 